\title{
Normal Thyroid Function in 32 Patients with Amyotrophic Lateral Sclerosis
}

\author{
Yasuo IWASAKI and Masao KINOSHITA
}

\begin{abstract}
Thyroid function tests were evaluated in 32 patients with amyotrophic lateral sclerosis (ALS) with radioimmunoassay of triiodothyronine, thyroxine, thyroid-stimulating hormone, and free thyroxine. The presence of antithyroid antibody activities were also tested. All patients were found to have normal thyroid values except one, who had low triiodothyronine and all patients had negative for antithyroid antibody activities. The data suggest that ALS could not be related to a thyroid disorder.
\end{abstract}

Key words: $\quad$ Amyotrophic lateral sclerosis, Thyroid function test, Euthyroid state

Amyotrophic lateral sclerosis (ALS) is a tragic disorder of the human nervous system that compromises upper and lower motor neurons, resulting in weakness and dysfunction of extremities and/or bulbar musculature. Despite intensive investigation, the etiopathogenesis is still unknown. No documental data are presently available that support a relationship of ALS to a viral infection, toxic metals, or any other causative agents or circumstance. A number of conditions are associated with motor neuron dysfunction, but not seem to be responsible for the common sporadic form of ALS. Lead (1), plasma cell dyscrasia (2), and pancreatic dysfunction (3) all have been associated with motor neuron disease syndromes. An autoimmune pathogenesis is suggested by the presence of immune system abnormalities in ALS (4). However, only few reports have been studied concerning the iodine metabolism and thyroid function in patients with ALS (5-7). In this report, we have examined the patients with ALS to determine whether thyroid alterations are present or not.

\section{MATERIALS AND METHODS}

Since 1969 the diagnosis of ALS was established in our department in more than sixty patients by history, clinical and laboratory examination, electrophysiological study, and muscle biopsy. Thyroid function tests were determined in 32 (20 men and 12 women aged 26 to 64 years (means 52.7 years)) of these patients. The control group consisted of 50 non-neurological patients (8).

In all patients the serum concentration of triiodothyronine $\left(\mathrm{T}_{3}\right)$, thyroxine $\left(\mathrm{T}_{4}\right)$, thyroidstimulating hormone (TSH), and free $\mathrm{T}_{4}$ were measured by the radioimmunoassay. All sera were also tested for the presence of antithyroid antibody activities (antithyroglobulin (Tab), antimicrosomal antibody (Mab)) by the commercial hemagglutination tests. No patients were receiving any medication known to influence thyroid function assessment. With statistical variable as $\mathrm{T}_{3}, \mathrm{~T}_{4}, \mathrm{TSH}$, free $\mathrm{T}_{4}$, $\mathrm{Tab}$, and Mab, the following tests were performed: calculation of mean values ( \pm standard deviation), examination for the normal range and Student's $\mathrm{t}$-test. The limit of significance was $\mathrm{p}<0.05$.

\section{RESULTS AND DISCUSSION}

The results of thyroid function tests and the frequency of the circulating antithyroid antibody titers

From The Fourth Department of Internal Medicine, Toho University Ohashi Hospital, Tokyo

Received for publication September 20, 1988.

Reprint request to: Yasuo Iwasaki, MD, The Fourth Department of Internal Medicine,

Toho University Ohashi Hospital, 2-17-6 Ohashi, Meguro-ku, Tokyo 153, Japan 
Table. Thyroid function and circulating thyroid antibodies in patients with amyotrophic lateral sclerosis and control subjects

\begin{tabular}{lcccc}
\hline \multirow{2}{*}{$\begin{array}{l}\text { Thyroid Function } \\
\text { Tests }\end{array}$} & $\begin{array}{l}\text { Normal } \\
\text { Range }\end{array}$ & $\begin{array}{c}\text { Pll }(\mathrm{n}=32) \\
\text { Mean } \pm \mathrm{SD}\end{array}$ & $\begin{array}{c}\text { Male }(\mathrm{n}=20) \\
\text { Mean } \pm \mathrm{SD}\end{array}$ & $\begin{array}{c}\text { Female }(\mathrm{n}=12) \\
\text { Mean } \pm \mathrm{SD}\end{array}$ \\
\cline { 3 - 5 } $\mathrm{T}_{3}, \mathrm{ng} / \mathrm{dl}$ & $70-190$ & $103.9 \pm 39.2$ & $101.2 \pm 41.0$ & $108.7 \pm 38.0$ \\
\hline $\mathrm{T}_{4}, \mu \mathrm{g} / \mathrm{dl}$ & $5.0-13.0$ & $8.7 \pm 1.5$ & $8.7 \pm 1.5$ & $8.6 \pm 1.8$ \\
\hline $\begin{array}{l}\mathrm{TSH}, \mu \mathrm{U} / \mathrm{ml} \\
\text { free } \mathrm{T}_{4}, \mathrm{ng} / \mathrm{dl}\end{array}$ & $1.1-2.0$ & $3.6 \pm 1.8$ & $3.6 \pm 2.5$ & $3.9 \pm 1.0$ \\
\hline $\begin{array}{l}\text { Antithyroid } \\
\begin{array}{l}\text { antibody titers } \\
\text { T-ab }\end{array}\end{array}$ & $1.4 \pm 0.1$ & $1.4 \pm 0.1$ & $1.4 \pm 0.1$ \\
\hline \begin{tabular}{l}
$\mathrm{M}$-ab \\
\hline
\end{tabular} & & none & none & none \\
\hline
\end{tabular}

$\mathrm{T}_{3}$ : triiodothyronine, $\mathrm{T}_{4}$ : thyroxine, $\mathrm{TSH}$ : thyroid-stimulating hormone, Tab: antithyroglobulin antibody, Mab: antimicrosomal antibody, ALS: amyotrophic lateral sclerosis, SD: standard deviation

were summarized in the Table. The $\mathrm{T}_{3}, \mathrm{~T}_{4}, \mathrm{TSH}$ and free $T_{4}$ levels were found to be within the normal range, except for only one patient, who exhibited low level of $T_{3}(15 n g / d l)$. This patient did not have a hypothyroidism, but considering to be in a low $T_{3}$ syndrome. There were not statistically significantly different between patients with ALS and the normal subjects. Thyroid antibodies were not detectable in the sera of all patients with ALS. No patients exhibited the thyroid enlargement.

The etiology of ALS is still obscure. Motor neuron diseases have been associated with several different disorders (9), viral infections (10), heavy metal intoxications (1), metabolic deficiencies $(2,3)$, and immunological disturbances (4),

An autoimmune pathogenesis is suggested by the presence of immune system abnormalities in patients with ALS (4). However, the evidence implicating immunological abnormalities is inconclusive. Hyperthyroidism may cause a variety of neurological disorders (11) and some of these syndromes have to be considered in the differential diagnosis of ALS, but only few reports are available concerning the thyroid function studies in patients with ALS (5-7). The purpose of this study was to evaluate whether there was any thyroid alterations in patients with ALS. However, the main results of this studies were normal thyroid parameters found in the all patients with ALS except the only one being low $\mathrm{T}_{3}$ level, and all patients had negative for antithyroid antibody activities.

In the literatures two patients with ALS and hyperthyroidism were described (12). McMenamin and Croxson (6) reported motor neuron disease with coexisting hyperthyroid Graves' disease and circulating thyroid autoantibodies were also detected in that case, suggesting the nature of motor neuron disease and the detection of circulating autoantibodies warranted speculation on a possible immunological association. Kiessling (6) reported normal range of thyroid functions and no evidence of thyroid antibodies in 44 patients with ALS. Appel et al. (7) reported eleven of 58 patients with ALS had evidence of thyroid disease and 6 had a thyroiditis.

Unfortunately there were no opportunity to accomplish the study by scintilating thyroid scan and a suppression test to give additional proof of noncoexisting thyroid autonomy.

In conclusion, we found normal thyroid values in patients with ALS and ALS could not be related to thyroid disorders. 
Thyroid Function in ALS

\section{REFERENCES}

1) Boothby JA, de Jesus PV and Rowland LP: Reversible forms of motor neuron disease: Lead 'neuritis'. Arch Neurol 31: 18, 1974.

2) Bauer M, Bergstrom R, Ritter B, et al: Macroglobulinemia: Waldenström and motor neuron syndrome. Acta Neurol Scand 55: 245, 1977.

3) Williams CJ: Amyotrophy due to hypoglycemia. Br J Med 1: 707, 1955.

4) Hoffman PM, Robbins DS, Nolte MT, et al: Cellular immunity in amyotrophic lateral sclerosis and parkinson-dementia. N Eng J Med 299: 680, 1978.

5) Kissling WR: Thyroid function in 44 patients with amyotrophic lateral sclerosis. Arch Neurol 39: 241, 1982.

6) McMenamin J and Croxson M: Motor neuron disease and hyperthyroid Graves' disease: a chance association? J Neurol Neurosurg Psychiatry 43: 46, 1980.

7) Appel SH, Stockton-Appel V, Stewart SS, et al: Amyotrophic lateral sclerosis, associated clinical disorders and immunological evaluations. Arch Neurol 43: 234, 1986.

8) Iwasaki $Y$ and Kinoshita $M$ : Thyroid function in patients with multiple sclerosis. Acta Neurol Scand 77: 269, 1988.

9) Johnson WG: The clinical spectrum of hexosaminidase A deficiency disease. Neurology 31: 1453, 1981.

10) Pertschuck LP, Bromme JD, Brigata DH, et al: Jejunal immunopathology in amyotrophic lateral sclerosis and immunofluorescence. Lancet 1: 1119, 1977.

11) Bradley WG and Walton JN: Neurologic manifestations of thyroid disease. Postgrad Med 50: 118, 1971.

12) Mager J: Myotrophe Lateralskerose: Zwei ungewöhnliche Fälle. Nervenarzt 47: 261, 1976. 